\title{
Possible physical and thermodynamical evidence for liquid water at the Phoenix landing site
}

\author{
Nilton O. Rennó, ${ }^{1,2}$ Brent J. Bos, ${ }^{3}$ David Catling, ${ }^{4}$ Benton C. Clark, ${ }^{5}$ Line Drube, ${ }^{6}$ \\ David Fisher, ${ }^{7}$ Walter Goetz, ${ }^{8}$ Stubbe F. Hviid, ${ }^{6}$ Horst Uwe Keller, ${ }^{8}$ Jasper F. Kok, ${ }^{1,2}$ \\ Samuel P. Kounaves, ${ }^{9}$ Kristoffer Leer, ${ }^{6}$ Mark Lemmon, ${ }^{10}$ Morten Bo Madsen, ${ }^{6}$ \\ Wojciech J. Markiewicz, ${ }^{8}$ John Marshall, ${ }^{11}$ Christopher McKay, ${ }^{12}$ Manish Mehta, ${ }^{1}$ \\ Miles Smith, ${ }^{13}$ M. P. Zorzano, ${ }^{14}$ Peter H. Smith, ${ }^{15}$ Carol Stoker, ${ }^{12}$ \\ and Suzanne M. M. Young ${ }^{16}$
}

Received 7 February 2009; revised 24 June 2009; accepted 7 July 2009; published 14 October 2009.

[1] The objective of the Phoenix mission is to determine if Mars' polar region can support life. Since liquid water is a basic ingredient for life, as we know it, an important goal of the mission is to determine if liquid water exists at the landing site. It is believed that a layer of Martian soil preserves ice by forming a barrier against high temperatures and sublimation, but that exposed ice sublimates without the formation of the liquid phase. Here we show possible independent physical and thermodynamical evidence that besides ice, liquid saline water exists in areas disturbed by the Phoenix Lander. Moreover, we show that the thermodynamics of freeze-thaw cycles can lead to the formation of saline solutions with freezing temperatures lower than current summer ground temperatures on the Phoenix landing site on Mars' Arctic. Thus, we hypothesize that liquid saline water might occur where ground ice exists near the Martian surface. The ideas and results presented in this article provide significant new insights into the behavior of water on Mars.

Citation: Rennó, N. O., et al. (2009), Possible physical and thermodynamical evidence for liquid water at the Phoenix landing site, J. Geophys. Res., 114, E00E03, doi:10.1029/2009JE003362.

\section{Introduction}

[2] The water vapor pressure at the triple point of water $(\sim 600 \mathrm{~Pa})$ is below the present-day atmospheric pressure on the lowest regions of Mars such as the Phoenix landing site $(\sim 700-800 \mathrm{~Pa})$, but the low surface temperature $(\sim 180-$ $250 \mathrm{~K})$ and dry air of these regions inhibits the presence of pure liquid water near the surface [e.g., Haberle et al., 2001; Whiteway et al., 2009]. However, liquid saline water can be present where a source of water (e.g., near-surface ground ice) exists because many salts depress the freezing temperature below present-day surface temperature in these regions [e.g., Farmer, 1976; Clark, 1978; Brass, 1980; Clark and Van Hart, 1981; Moore and Bullock, 1999;

${ }^{1}$ Department of Atmospheric, Oceanic, and Space Sciences, University of Michigan, Ann Arbor, Michigan, USA.

${ }^{2}$ Applied Physics Program, University of Michigan, Ann Arbor, Michigan, USA.

${ }^{3}$ NASA Goddard Space Flight Center, Greenbelt, Maryland, USA.

${ }^{4}$ Department of Earth and Space Sciences, University of Washington, Seattle, Washington, USA.

${ }^{5}$ Space Science Institute, Boulder, Colorado, USA.

${ }^{6}$ Niels Bohr Institute, University of Copenhagen, Copenhagen, Denmark.

${ }^{7}$ Geological Survey of Canada, University of Ottawa, Ottawa, Canada.

Copyright 2009 by the American Geophysical Union.

0148-0227/09/2009JE003362
Bryson et al., 2008; Haberle et al., 2001; Chevrier and Altheide, 2008]. Indeed, the presence of even salts with relatively high freezing point temperatures such as $\mathrm{NaCl}$ might allow liquid water to form sporadically on the surface of Mars [Haberle et al., 2001]. On Earth, except in some deserts, salts are leached from the crust and carried to the subsurface or the sea, but on Mars leaching is inhibited by the dry climate and salts become available to absorb water from the atmosphere and subsurface ice, and form liquid solutions. Here we report the discovery of possible evidence for liquid saline water or brines in areas disturbed by the Phoenix Lander. Moreover, we postulate that layered ice, such as that found on two trenches excavated by the Phoenix's robotic arm (RA), form in the presence of brines.

\footnotetext{
${ }^{8}$ Max Planck Institute for Solar System Research, Katlenburg-Lindau, Germany.

${ }^{9}$ Department of Chemistry, Tufts University, Medford, Massachusetts, USA.

${ }^{10}$ Department of Atmospheric Sciences, Texas A\&M University, College Station, Texas, USA.

${ }^{11}$ Carl Sagan Center, SETI Institute, Mountain View, California, USA.

${ }^{12}$ NASA Ames Research Center, Mountain View, California, USA.

${ }^{13}$ Jet Propulsion Laboratory, California Institute of Technology, Pasadena, California, USA.

${ }^{14}$ Centro de Astrobiología, Madrid, Spain.

${ }^{15}$ Department of Planetary Sciences, University of Arizona, Tucson, Arizona, USA.

${ }^{16}$ Department of Chemistry, University of New Hampshire, Durham, New Hampshire, USA.
} 


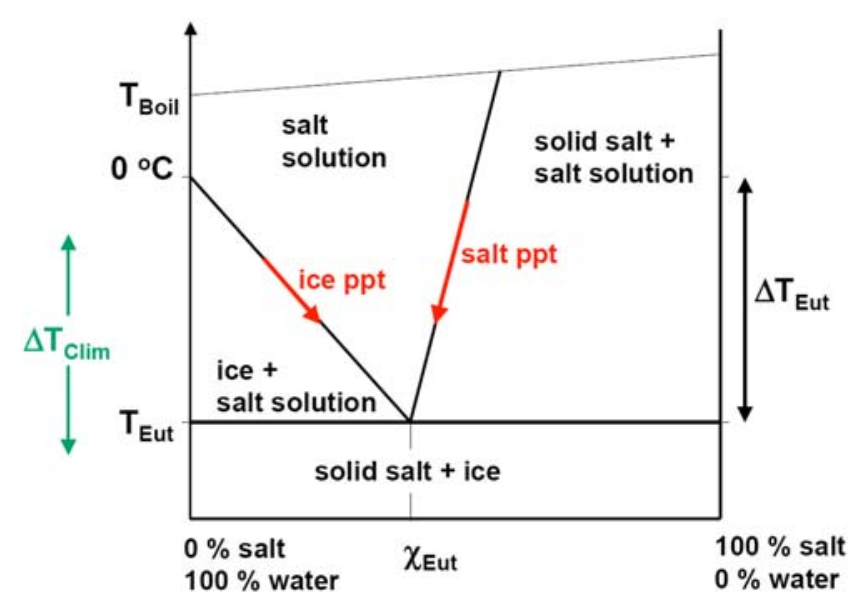

Figure 1. Sketch of the phase diagram of the aqueous solution of a generic salt (note that in real diagrams, the curves leading to the eutectic mixture are not straight lines). We hypothesize that eutectic solutions form naturally during freeze-thaw cycles. This happens because pure water ice precipitates when diluted mixtures are cooled and their salt concentration increases until the eutectic temperature is reached. Then, the eutectic mixture freezes. On the other extreme, salts precipitate when concentrated mixtures are cooled until the eutectic concentration is reached and the entire solution freezes. Therefore, freeze-thaw cycles ranging from diurnal to geological timescales lead to the formation of pockets of eutectic solutions that can be liquid even on present-day Mars.

This suggests that liquid saline water is also present in areas of Mars not disturbed by the Phoenix Lander.

[3] Deliquescent materials, mostly salts, absorb water when exposed to the atmosphere, and form liquid solutions when the relative humidity is above a threshold value known as the deliquescence relative humidity, $R H_{D}$ [e.g., Seinfeld and Pandis, 2006]. However, the solutions usually remain liquid until the relative humidity falls below a much lower value known as the efflorescence relative humidity, $R H_{E F}$ [e.g., Seinfeld and Pandis, 2006]. The $R H_{D}$ of mixture of salts is always lower than that of the individual salts and can be smaller than 0.1 [e.g., Cohen et al., 1987; Seinfeld and Pandis, 2006]. Besides absorbing water, salts depress the freezing point temperature and therefore reduce the vapor pressure of aqueous solutions, lowering their boiling point pressure. This is important because, on Mars, the atmospheric pressure is of the order of the vapor pressure at the triple point of water. The lowest temperature at which aqueous saline solutions freeze, known as their eutectic temperature, can be lower than $200 \mathrm{~K}$ [e.g., Pestova et al., 2005; Seinfeld and Pandis, 2006]. The solution with this minimum freezing temperature, known as a eutectic mixture, has salt mass fraction $\chi_{E u t} \sim 0.3-0.5$ for salts such as $\mathrm{NaCl}$ and perchlorate of sodium and magnesium. The freezing point depression $\Delta T_{E u t}$ of saline solutions depends on their composition. Above the eutectic temperature only deliquescence is possible, but below it, aqueous solutions can be supersaturated with respect to ice, and therefore both deliquescence and ice formation are possible [e.g., Koop et al., 2000; Braban et al., 2001; Seinfeld and Pandis, 2006]. Indeed, it has been shown that even complex NaCl-rich natural solutions such as seawater remain partially liquid at temperatures as low as $230 \mathrm{~K}$ [e.g., Koop et al., 2000].

\section{Formation of Brines and Salt Layers}

[4] Brine layers are observed near the surface when seawater freezes [Bushuyev et al., 1974], and at about $2-10 \mathrm{~cm}$ below the surface in Antarctica's Dry Valleys, a good Mars analog [Dickinson and Rosen, 2003; Wentworth et al., 2005]. The idea that brines exist or at least have existed on Mars is consistent with the evidence of aqueous alteration in Mars meteorites while they were on Mars [Gooding et al., 1991]. Finally, brines have a large dielectric constant that can cause the attenuation of radar signals suggested by recent measurements by Mars orbiters [Grimm and Stillman, 2008]. Salt layers such as those observed in the soils of Antarctic Dry Valleys [Dickinson and Rosen, 2003], desert loess, and Mars duricrust are examples of soils modified by saline solutions that might have pockets of extremely high salt concentrations [e.g., Goudie, 1986].

[5] Figure 1 shows a sketch of the phase diagram of a generic single-salt solution with the climate process postulated to produce eutectic solutions indicated. The phase diagram for the multicomponent solutions expected in nature is more complex, but this simple diagram illustrates the thermodynamical process that leads to the formation of eutectic solutions. The green double arrow labeled $\Delta T_{\text {Clim }}$ indicates the amplitude of the temperature variation during arbitrary cycles ranging from diurnal to geological timescales. We postulate that eutectic solutions form when the soil temperature oscillates around the eutectic temperature $T_{E u t}$. This happens because ice precipitates when solutions with salt concentration smaller than $\chi_{E u t}$ are cooled. This is analogous to desalination by natural freezing, a process in which ice precipitates and separates from the remaining solution, of higher concentration, when the temperature of the mixture falls below its freezing point value [Wankat, 1973]. Water molecules from the ice that precipitates from the solution become available to diffuse into deliquescent salts if any are present in the soil. The process postulated above would drive the concentration of the solution toward the eutectic value, and even a single 'temperature cycle' can increase the concentration of the solution by a factor of $2-6$ [Wankat, 1973].

[6] On Mars, $\Delta T_{E u t} \sim 70 \mathrm{~K}$ even for single salts discovered at the Phoenix landing site and $T_{E u t}$ is below surface temperatures [Pestova et al., 2005; Hecht et al., 2009]. Because of the large $\Delta T_{E u t}$ of these salts, eutectic solutions can form and remain liquid almost anywhere that there is enough water (i.e., where there is water ice near the surface and/or $R H>R H_{D}$ ). Since it has been shown that even eutectic solutions of single salts with modest freezing point depression such as $\mathrm{NaCl}\left(\Delta T_{E u t} \sim 20 \mathrm{~K}\right)$ can sporadically be liquid on Mars [Haberle et al., 2001], liquid eutectic brines of perchlorates might be more common.

[7] Phoenix's Wet Chemistry Laboratory (WCL) found significant amounts (about $1 \%$ by mass) of perchlorates and magnesium ions in the soil of the landing site; probably from magnesium perchlorate hydrates [Hecht et al., 2009]. 
However, many other salts including sulfates and calcium carbonate are also probably present in the soil as suggested by data from previous Mars missions and meteorites [e.g., Rao et al., 2005; Wentworth et al., 2005]. This is important because $\mathrm{Mg}\left(\mathrm{ClO}_{4}\right)_{2} \cdot n \mathrm{H}_{2} \mathrm{O}$ and $\mathrm{Ca}\left(\mathrm{ClO}_{4}\right)_{2} \cdot m \mathrm{H}_{2} \mathrm{O}$ have freezing temperatures of about $200 \mathrm{~K}$, are extremely deliquescent [Besley and Bottomley, 1969; Pestova et al., 2005], and mixtures of salts have eutectic temperatures below those of the individual salts [e.g., Seinfeld and Pandis, 2006]. This suggests that the formation of eutectic solutions is possible at the present time on Mars, where ground ice exists near the surface such as at the Phoenix landing site. However, it is important to point out that the solubility of salts in aqueous solutions decreases with temperature making deliquescence more difficult on Mars than on Earth.

\section{Interaction of the Phoenix Landing Thruster Plumes With the Martian Soil}

[8] Phoenix used a simple hydrazine powered rocket engine pulsating at $10 \mathrm{~Hz}$ to land softly on Mars. The thruster plumes produced by this engine excavated the soil, exposing the subsurface ice under the spacecraft (M. Mehta et al., Explosive erosion during the Phoenix landing exposes subsurface ice on Mars, submitted to Icarus, 2009). The dynamics of the interaction of the thruster plume with the surface was studied by solving the momentum, energy and mass conservation equations for a compressible fluid with the FLUENT numerical solver. The simulations show that the plume is collimated and that the flow reaches supersonic speeds even near the surface [Plemmons et al., 2008; Mehta et al., submitted manuscript, 2009].

[9] The depth of the topsoil (ice-free soil) at the Phoenix landing site varies between 3 and $18 \mathrm{~cm}$ [Smith et al., 2009]. Laboratory experiments with a thruster simulator designed and fabricated at the University of Michigan show that the plume penetrates into the soil and excavates it down to the ice layer, even when the topsoil layer is as deep as $20 \mathrm{~cm}$ (Mehta et al., submitted manuscript, 2009). Images acquired by the Phoenix robotic arm camera (RAC) clearly show that the topsoil was completely removed, exposing the subsurface ice under the lander as predicted by laboratory simulations (Mehta et al., submitted manuscript, 2009). The compression of the plume over the ice produced pressure and temperature perturbations of about $10-35 \mathrm{kPa}$ and $1000 \mathrm{~K}$. This caused a $\sim 1 \mathrm{~mm}$ thick layer of ice to melt and salty mud to be splashed under the lander [Plemmons et al., 2008].

[10] In order to minimize contamination, Phoenix used high purity hydrazine to power its engines. The byproducts of the combustion of hydrazine are water vapor, nitrogen, hydrogen and ammonia. Tests with the Phoenix thruster engine show no hydrazine in the plume above a detection level of $0.2 \%$ [Plemmons et al., 2008]. Moreover, since hydrazine freezes at about $275 \mathrm{~K}$, any traces of hydrazine would freeze at the landing site temperatures. Thus, except for possible trace amounts of fuel impurities, ammonia is the only contaminant from the Phoenix thruster plume. However, the high temperature of the plume coupled with the high volatility of ammonia would force it to evaporate quickly, leaving only trace amounts in the soil. Indeed, since the fugacity of ammonia is much larger than that of water under ambient Martian conditions [e.g., Edwards et al., 1975, 1978; Xu and Goswami, 1999], ammonia in concentrated aqueous solutions would evaporate quickly into the ammonia-free Martian atmosphere and inhibit deliquescence.

[11] It is possible that unknown chemical reactions between the hot gases of the Phoenix thruster plume and the subsurface ice or soil could produce deliquescent materials. However, analysis of images of the landing site, in combination with data from our landing simulations, indicates that about $150 \mathrm{~kg}$ of soil was removed by Phoenix thruster plume and $0.37 \mathrm{~kg}$ of ammonia was ejected during terminal descent (Mehta et al., submitted manuscript, 2009). Thus, even if all ammonia ejected during terminal descent had been mixed with the soil, its concentration would not exceed $0.5 \%$ (by mass). This concentration is smaller than that of the perchlorate salts detected by WCL. Therefore, it is less probable that ammonia, or unknown products of its chemical reactions with the soil, has splashed onto the strut than nonvolatile perchlorate salts. Finally, the fact that the Phoenix's WCL and Thermal Evolved Gas Analyzer (TEGA) did not detect hydrazine, ammonia or their hydrates in the soil (including soil altered by the landing thruster plumes) [Boynton et al., 2009; Hecht et al., 2009; Smith et al., 2009] further reduces the probability that contamination might have occurred.

[12] Detailed studies of contaminant by the Viking Lander thruster engines in the 1970 s showed that less than a few $100 \mathrm{ppm}$ of ammonia remained in the soil even after it was exposed to the thruster plumes for more than 20 times the value for the Phoenix plumes [Romine and Gliozzi, 1973; Husted and Fennessey, 1977]. Therefore, we conclude that it is unlikely that ammonia or its hydrates are responsible for the formation of the spheroids observed on a strut of its leg as shown below.

\section{Possible Physical Evidence for Liquid Water \\ 4.1. Spheroids Grow and Move}

[13] The impingement of the Phoenix landing thruster plumes on the surface of Mars removed the topsoil, exposed the subsurface ice, and splashed any brine present between the surface and the subsurface ice around as suggested by numerical simulations and laboratory experiments [Plemmons et al., 2008; Renno et al., 2009; Mehta et al., submitted manuscript, 2009]. Keller et al. [2009] showed that some of the Phoenix soil samples would not fall out of the scoop even when the scoop was pointed with the opening directly down. This happened because soil samples were very sticky and therefore we can confidently state that splashed soil could similarly adhere to the strut.

[14] Figures 2 and 3 show possible physical evidence that various oblate spheroids observed on a strut of the Phoenix leg could be liquid solutions that grew by deliquescence on splashed material, most probably a saline mud. The diffuse component of light scattered from wet or ice-covered objects is reduced by an amount proportional to the inverse of the square of the index of refraction [Jezek and Koh, 1987]. Since the index of refraction of liquid water is larger than that of water ice, liquefaction darkens water substance [Jezek and Koh, 1987; Perovich et al., 2002]. Thus, the 


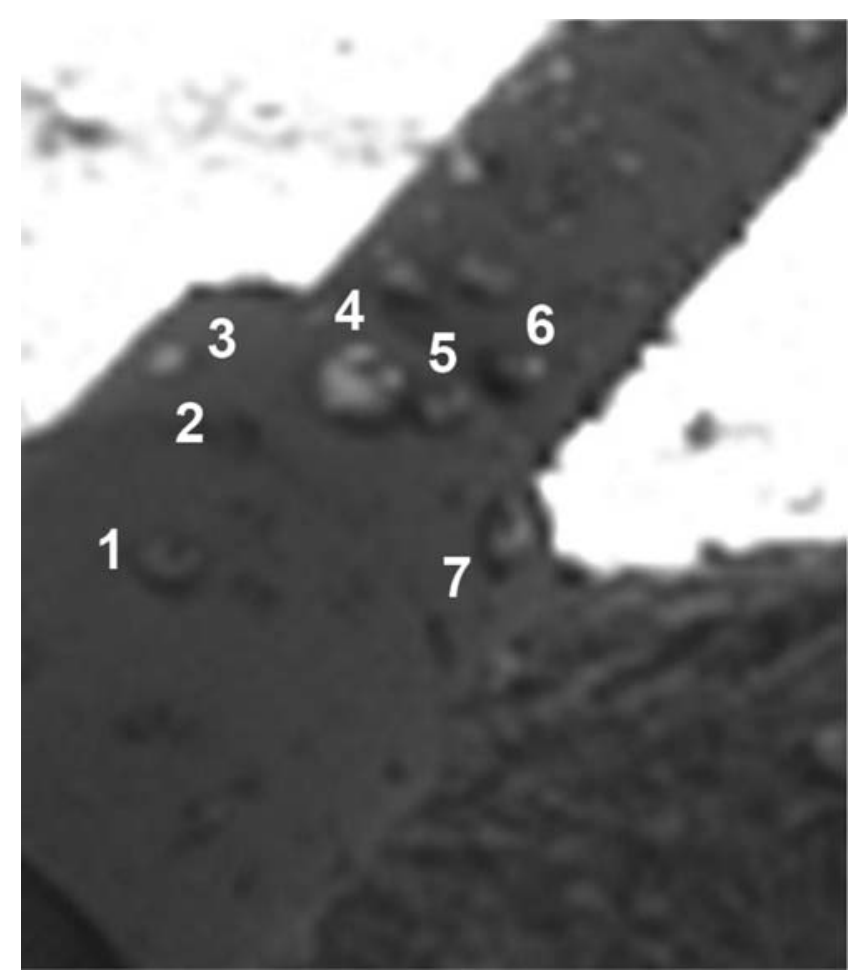

Figure 2. RAC image of a Phoenix strut on Sol 8 at 1445 local mean solar time (LMST). A few oblate spheroids that appear to grow by deliquescence are selected for analysis. Spheroid 4 appears to drip and partially merge with spheroid 5 as indicated in Figure 3.

darkening of some spheroids or portions of their surface probably indicates liquefaction. On Martian day (Sol) 31, the spheroid labeled 4 in Figure 2 has become substantially darker than other spheroids nearby. By Sol 44 this spheroid has disappeared almost completely, while nearby spheroids have grown. The darkening suggests that spheroid 4 liquefied and dripped. Indeed, the spheroids labeled 4 and 5 in Figure 2 appear to have also partially merged with each other between sols 8 and 31 as suggested by the sequence of images shown in Figure 3.

[15] Most spheroids exhibit substantial growth between sols 8 and 44, but not between sols 44 and 96 (see Figures 3 and 4 ). This suggests that the relative humidity with respect to the spheroids reached a peak value around Sol 44 and the spheroids' midafternoon salt concentration became small enough for their saturation vapor pressure to reach the value of the atmospheric vapor pressure, inhibiting further growth during the later period. However, further growth could also have been inhibited by decreases in atmospheric humidity in spite of sporadic measurements by Phoenix to suggest only small variations between sols [Smith et al., 2009]. As the spheroids grow, their salt concentration decreases and their freezing temperature increase. Thus, they might partially freeze when the temperature falls in the evening and melt again on the next Sol. The spheroids might also effloresce if the humidity falls below $R H_{E F}$. However, this is a complex process because a metastable liquid can be present after efflorescence producing spheroids of mixed phases (solid/ liquid) [Tang et al., 1997; Cziczo et al., 1997; Koop et al., 2000]. Moreover, since nucleation usually starts at the surface, an ice shell might form and variations of the internal pressure with temperature can cause spheroids to burst [Clausse et al., 1987]. Indeed, Figure 4 suggests the presence of burst and mixed phase spheroids toward the end of the mission (Sol 96) when it got colder.

\subsection{Smoking Guns}

[16] The "smoking gun" that spheroid 4 dripped from the strut and therefore has been liquid is the fact that it darkens just before disappearing, and that growth is suppressed only over the material on its original location. This suggests that
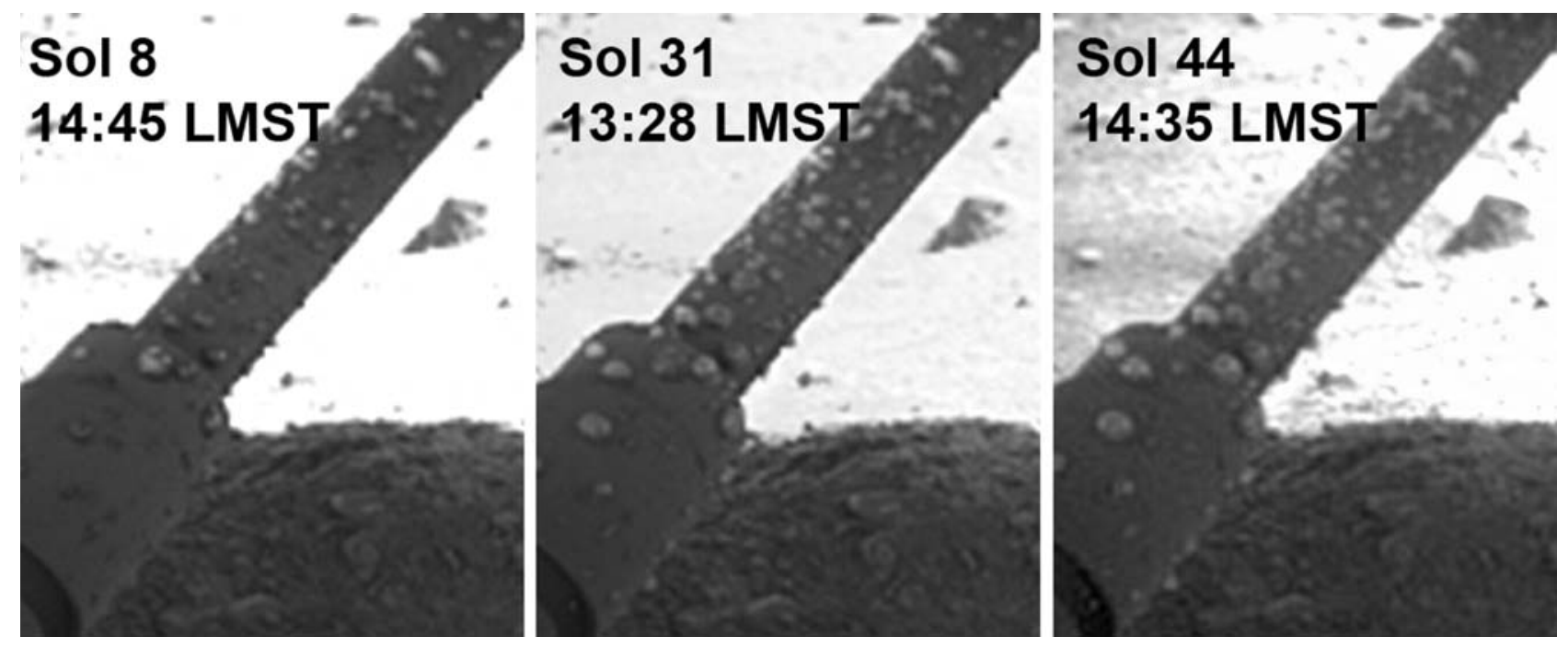

Figure 3. RAC images of the strut on sols 8, 31, and 44. The spheroids selected for study are marked on Figure 2. The "smoking gun" that spheroid 4 dripped off and, therefore, must have been liquid is the fact that it darkens just before disappearing and that growth is subsequently suppressed only over the material on its original location. The thinner part of the strut is $3.05 \mathrm{~cm}$ in diameter. 


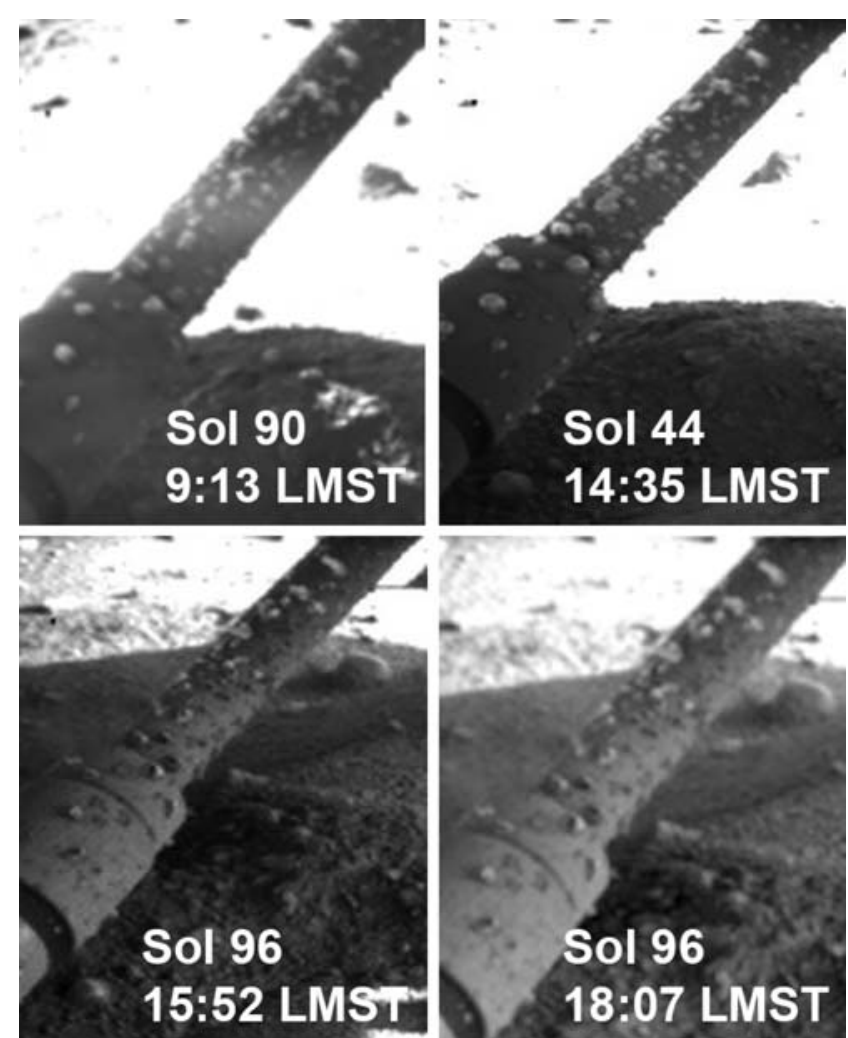

Figure 4. Appearance of the spheroids on the strut at various sols and times. The spheroids are largest and most spherical at around midafternoon on Sol 44, probably because the $R H$ and temperature have reached peak values. This supports the idea that these spheroids are liquid and grow by deliquescence. Spheroids are smaller on Sol 96, suggesting that the $R H$ over them dropped below $R H_{D}$ and they partially evaporated. They also could have shrunk because the temperature fell below the eutectic value and they froze and them sublimated. This is consistent with the passing of the summer solstice on Sol 30 and the quasi steadily decrease of the maximum and minimum diurnal air temperatures afterward. Indeed, the temperature was already about 5 K lower on Sol 96 than on Sol 44.

spheroid 4 carried most of its salts with it, when it dripped. Moreover, the "smoking gun" that the spheroids grow by deliquescence is the fact that they grow only over splashed material, and that their sizes and growth is consistent with a model in which growth is proportional to volume as described by equation (3) below. Finally, the spheroidal shape of various particles is also consistent with the presence of the liquid phase at least intermittently.

[17] A quantitative analysis of the images displayed on Figures 2 and 3, with uncertainty of about $10 \%$, shows that the pixel size of the images of the area containing the selected spheroids numbered 1 to 7 is about $0.2 \mathrm{~mm}$. The diameter of the spheroids between sols 8 and 96 is indicated in Table 1. Their diameters increase from between about 4.0 and $8.4 \mathrm{~mm}$ on Sol 8, to between 5.2 and $10.0 \mathrm{~mm}$ on Sol 44. The spheroids shrink between sols 44 and 96 to diameters ranging from about 1 to $6.6 \mathrm{~mm}$. It is shown in the appendix that spheroids of diameter of up to $10 \mathrm{~mm}$ in vertical surfaces, and $35 \mathrm{~mm}$ in horizontal surfaces are gravitationally stable if not perturbed.

\section{Possible Thermodynamical Evidence for Liquid Water}

\subsection{Spheroids Growth by Deliquescence}

[18] A lower bound to the temperature of the ice exposed under the lander is about $200-210 \mathrm{~K}$ [Mellon et al., 2004]. Assuming that the atmosphere under the lander is saturated with respect to the exposed ice, we find that the partial pressure of water vapor is about 0.3 to $2 \mathrm{~Pa}$. This is consistent with maximum near surface values of about 2 Pa measured by Phoenix's Thermal and Electrical Conductivity Probe (TECP) [Smith et al., 2009; A. P. Zent et al., manuscript in preparation, 2009]. Engineering temperature sensors located at the bottom of the instrument deck, near the top of the strut, indicate that the temperature varied between slightly above $200 \mathrm{~K}$ at around midnight to $240 \mathrm{~K}$ in the middle of the day, around the first 45 sols of the mission. The strut is colder than the bottom of the deck because it is attached to a leg sitting on a thin layer $(\sim 5 \mathrm{~cm}$ thick) of soil on top of ground ice. It is reasonable to assume that the strut temperature is between that of the exposed ice and the bottom of the deck; that is somewhere between about 200 and $220 \mathrm{~K}$. Thus, the spheroids observed on the strut could not grow if they were composed of pure water because the atmospheric partial pressure of water vapor is not larger than the saturation water vapor pressure of pure liquid water or ice, even during the coldest period of the Martian day. However, spheroids of solutions of deliquescent salts can easily grow in this environment. Indeed, the $R H_{D}$ of magnesium perchlorate 8 hydrate is about 0.5 [Besley and Bottomley, 1969]. Thus, water vapor partial pressure smaller than 0.3 to $2 \mathrm{~Pa}$ is sufficient to promote the growth of concentrated solutions of magnesium perchlorate 8 hydrate on the strut until they get diluted enough and stop growing. Finally, since the ice exposed under the lander (near the strut where spheroids grow) is sublimating [Keller et al., 2009], it is thermodynamically impossible for ice particles to grow on a warmer strut. This is additional possible evidence that deliquescent salts and liquid saline water are present at the Phoenix landing site.

[19] The saturation vapor pressure of saline solutions $\left(e_{S o l}\right)$ is lower than that over pure water:

$$
e_{S o l}=e_{S}\left(1-\frac{b}{r^{3}}\right)
$$

Table 1. Approximate Diameter of the Spheroids Observed on the Strut on Sols 8 at 1445 LMST, Sol 31 at 1328 LMST, Sol 44 at 1435 LMST, and Sol 96 at 1807 LMST $^{\mathrm{a}}$

\begin{tabular}{ccccc}
\hline Spheroid & $\begin{array}{c}\text { Sol 8 } \\
\text { Diameter } \\
(\mathrm{mm})\end{array}$ & $\begin{array}{c}\text { Sol 31 } \\
\text { Diameter } \\
(\mathrm{mm})\end{array}$ & $\begin{array}{c}\text { Sol 44 } \\
\text { Diameter } \\
(\mathrm{mm})\end{array}$ & $\begin{array}{c}\text { Sol 96 } \\
\text { Diameter } \\
(\mathrm{mm})\end{array}$ \\
\hline 1 & 4.8 & 7.4 & 9.4 & 6.6 \\
2 & $<1$ & 6.5 & 7.8 & 6.1 \\
3 & 4.0 & 5.9 & 6.1 & 4.2 \\
4 & 8.4 & 6.0 & 5.2 & $<1$ \\
5 & 4.3 & 7.0 & 8.6 & 5.5 \\
6 & 4.8 & 7.7 & 10.0 & 6.1 \\
7 & 6.3 & 9.2 & 10.0 & 6.0 \\
\hline
\end{tabular}

${ }^{a}$ LMST, local mean solar time. The spheroids are labeled in Figure 2. 
where $e_{S}$ is the vapor pressure over a flat surface of pure water, $r$ is the (spheroid) droplet's radius, and

$$
b=\frac{3 i m_{H_{2} O}}{4 \pi \rho_{\text {liq }} m_{\text {salt }}} \rho_{\text {salt }} V_{\text {in }}
$$

where $i$ is the degree of ionization of the salt, $m_{\mathrm{H}_{2} \mathrm{O}}$ and $m_{\text {salt }}$ are the molar masses of water and the salt, $\rho_{\text {liq }}$ and $\rho_{\text {salt }}$ are the densities of liquid water and the salt, and $V_{i n}$ is the volume of the salt solute (the initial volume) [Rogers, 1979]. It follows from the above that the ratio of the initial volume of the salt particle to the equilibrium volume of the aqueous solution spheroid is

$$
\frac{V_{e q}}{V_{\text {in }}}=\frac{1}{1-R H} \frac{i m_{\mathrm{H}_{2} \mathrm{O}}}{m_{\text {salt }}} \frac{\rho_{\text {salt }}}{\rho_{\text {liq }}},
$$

where $R H \approx e_{S o l} / e_{S} \geq R H_{D}$ is the relative humidity with respect to the solution (at the strut temperature). Spheroids of aqueous solutions grow when the $R H$ exceeds $R H_{D}$, and shrinks when the $R H$ is reduced, but they crystallize only after the $R H$ falls below the usually much lower $R H_{E F}$ [Cohen et al., 1987]. Since the dominant salts at the landing site are probably sodium and magnesium perchlorates [Hecht et al., 2009], we take $i \approx 2-3, m_{\text {salt }}=223 \mathrm{~g} \mathrm{~mol}^{-1}$, $\rho_{\text {salt }}=2.6 \mathrm{~g} \mathrm{~cm}^{-3}$ and $R H_{D} \sim 0.5$. Equation (3) can be used to estimate the increase in their volume when they grow by deliquescence as a function of the $R H$ over the spheroids. We find that $V_{e q} \sim 2 V_{i n}$ when the $R H$ exceeds the deliquescence value by small amounts $(\sim 0.1)$. However, they can grow by a much larger fraction if $R H \gg R H_{D}$. Indeed, when $R H \geq R H_{D}$ the spheroids stops growing only after they get into equilibrium with the environment or get sufficiently diluted and freeze. Doubling the mass of water in the eutectic solution of magnesium and calcium perchlorate hydrates increases their freezing temperature from about 200 to $250 \mathrm{~K}$ [Besley and Bottomley, 1969]. The observed growth indicated in Table 1 are similar to that predicted by deliquescence. The only spheroid that shrank between sols 8 and 44 was spheroid 4 after Sol 31, the one that appears to have dripped and either merged with his neighbor or fallen from the strut. This supports the idea that at least spheroid 4 was entirely liquid because the removal of deliquescent salts would inhibit further growth at its prior location.

\subsection{Spheroids Growth Rate}

[20] Assuming that the spheroids grow by deliquescence, their growth rate is of the same order as that of spherical droplets. In this case, it follows from Rogers [1979] that

$$
r \frac{d r}{d t}=\frac{R H-1+b / r^{3}}{f_{k}+f_{d}}
$$

where $r$ is the droplet's radius, $t$ is time, ambient $R H$ is the ambient relative humidity with respect to a flat surface of water at the spheroids' temperature, $b$ is a constant that accounts for the effect of salts on the saturation water vapor pressure as indicated above, and

$$
\begin{gathered}
f_{k}=\left(\frac{L}{R_{v} T}-1\right) \frac{L \rho_{l i q}}{K T}, \\
f_{d}=\frac{\rho_{l i q} R_{v} T}{e_{S} D},
\end{gathered}
$$

where $L$ is the latent heat of vaporization of water, $R_{\mathrm{V}}$ is the specific gas constant for water vapor, $T$ is the absolute temperature, $K \approx 0.01 \mathrm{~W} \mathrm{~m}^{-1} \mathrm{~K}^{-1}$ is the thermal conductivity of Martian air (this value is for $\mathrm{CO}_{2}$ at $200 \mathrm{~K}$ and is independent of pressure) [Lide, 2008a], $D \approx 0.001 \mathrm{~m}^{2}$ $\mathrm{s}^{-1}$ is the molecular diffusion coefficient of Martian air [Lide, 2008b; Marrero and Mason, 1972], and $e_{S}$ is the saturation vapor pressure with respect to a flat surface of pure water. Taking the supersaturation to be 0.1 (that is, $\left.R H-1+b / r^{3}=0.1\right)$, we find that the growth rate of a saline droplet at $220 \mathrm{~K}$ is

$$
\frac{d r}{d t} \approx \frac{C}{r}
$$

where $C=\frac{0.1}{f_{k}+f_{d}}=2 \times 10^{-12} \mathrm{~m}^{2} \mathrm{~s}^{-1}$. The radius of the spheroids observed on the Phoenix strut ranges from about 1 and $5 \mathrm{~mm}$. Thus, their growth rate ranges from about 1 to $7 \mu \mathrm{m} \mathrm{h}^{-1}$. Since the spheroid's growth rates depends linearly on the supersaturation value; their growth rates would range from about 5 to $35 \mu \mathrm{m} \mathrm{h}^{-1}$ for a supersaturation of 0.5 . This is consistent with the observed growth rates suggested by the values presented in Table 1 .

\subsection{Additional Possible Evidence for Liquid Saline Water}

[21] Figure 5 shows a Phoenix's Optical Microscope (OM) image of a soil sample from the trench shown in Figure 6 after the ice sublimated. This sample has at least twice as many white specks as other soil samples. A substantial fraction of the ubiquitous white specks are probably salt particles such as the perchlorates and carbonates measured by Phoenix's Thermal Evolved Gas Analyzer (TEGA) and WCL [Boynton et al., 2009; Hecht et al., 2009; W. Goetz et al., Microscopic structure of soils at the Phoenix landing site, Mars: Classification and description of their optical and magnetic properties, submitted to Journal of Geophysical Research, 2009]. If the ice layer shown in Figure 6 were formed in salt layers such as those observed in the Dry Valleys of Antarctica and discussed in section 2, the Phoenix Robotic Arm would mix the thin brine layers with the soil during sampling. Thus, thin layers of brines would produce soil samples similar to that shown in Figure 5.

[22] Finally, the hypothesis here proposed suggest that the spheroids' grow as liquid when they are warm enough and $R H>R H_{D}$, they sublimate/evaporate when $R H<R H_{E F}$, and that they might also contain mixed solid/liquid phases. These predictions are in agreement with what is seen in images taken at various sols and local mean solar time (LMST), and with the temperature and humidity measurements at the landing site (see Figures 3, 4, 7, 8, and 9).

\section{Possible Alternative Explanations for the Spheroids}

[23] The most likely alternative explanations for formation of the spheroids observed on the strut are that they are either ice particles nucleated by the dark material splashed on the strut, or that they grew by deliquescence, but on contamination products of the thruster engines, not on natural salts from Mars. These two possibilities are discussed in this section. 


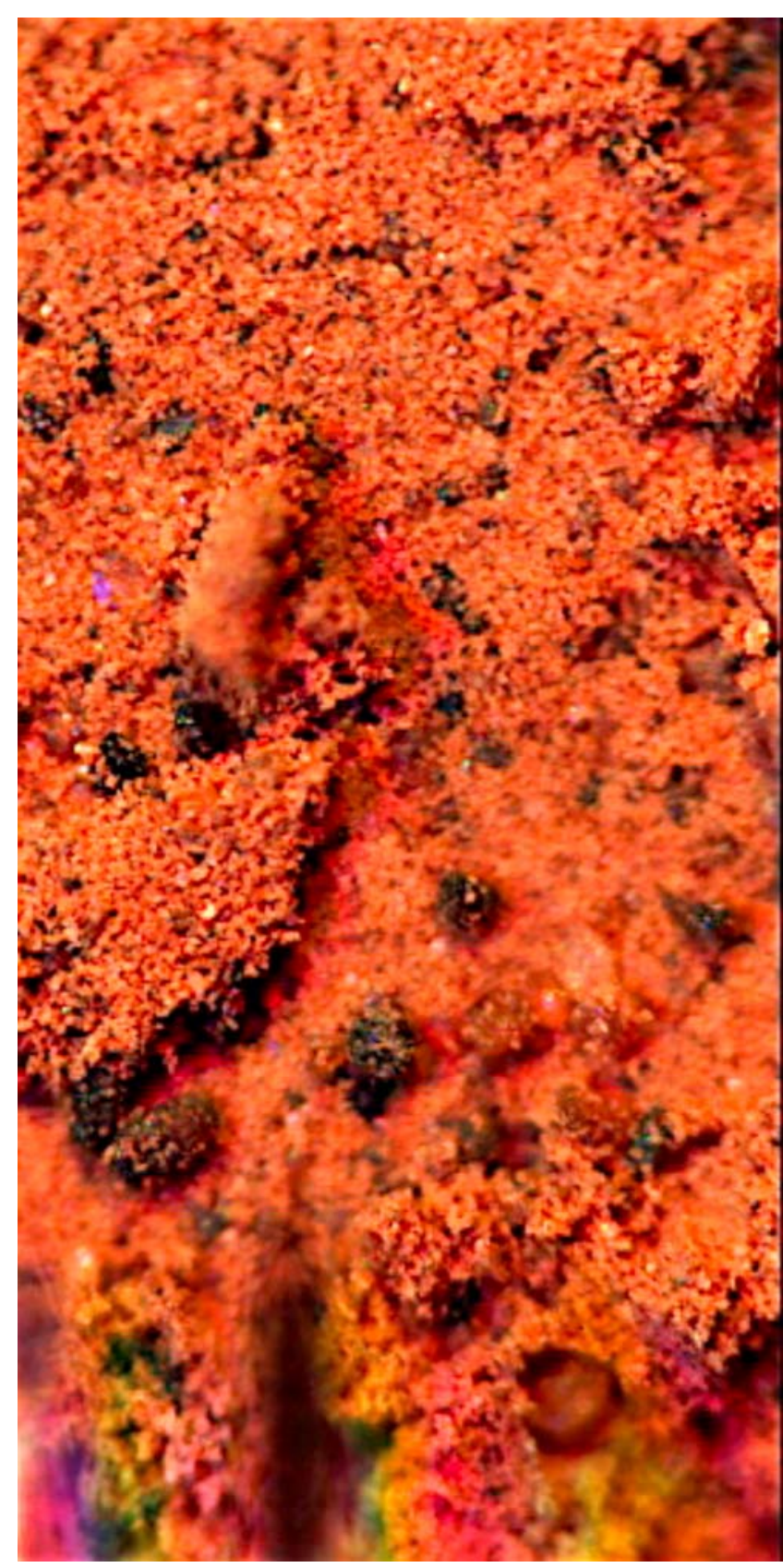

Figure 5. Possible evidence of salt particles in a full color OM image of a sample of soil from the Phoenix landing site. The image is $1 \mathrm{~mm}$ wide. A substantial fraction of the ubiquitous whitish particles are probably salts. This idea is consistent with measurements by the Phoenix TEGA and WCL.

[24] The growth of ice particles requires saturation with respect to ice on the dark material at approximately the temperature of the strut (but not on the strut itself otherwise a thin layer of ice would form on it). This requires the middle of the strut, where spheroids grow, to be colder than the sublimating ground ice [Markiewicz et al., 2009] near the leg of the lander. Since both, the sublimating ice and the strut are on the shadow of the warm lander, it is unlikely that the strut is colder than the ground ice (see Figure 8).
Indeed since the strut is under the lander deck, it exchanges thermal radiation mostly with it and the exposed ground ice. Moreover, since heat diffusion into the thin Martian air is small compared to heat transfer by thermal radiation and conduction between the bottom of the lander and the ground, the temperature of the strut is most probably somewhere between that of the exposed ground ice and the bottom of the instrument deck as also suggested by the results of our calculations displayed in Figure 8.

[25] If the spheroids were ice particles, their growth rate would depend mostly on the supersaturation of water vapor over ice at their particular temperature, and not primarily on their volume as suggested by the images and the calculations presented in section 5.1 (for example the three small particles just above spheroid 7 grows by a very small amount compared to the larger spheroids as suggested by Figure 3). In addition, the spheroids growth rate would be larger toward the end of the mission when it was colder and frost was frequently observed on the ground (Figure 9). However, instead of presenting larger growth rate, the spheroids appear to evaporate and/or sublimate toward the end of the mission as indicated by Figures 4 and 9 . Therefore, we argue that it is unlikely that the spheroids are ice particles.

[26] Ammonia is the main byproduct from the Phoenix thruster plume and the most likely contaminant. However, the high volatility of ammonia and its hydrates [e.g.,

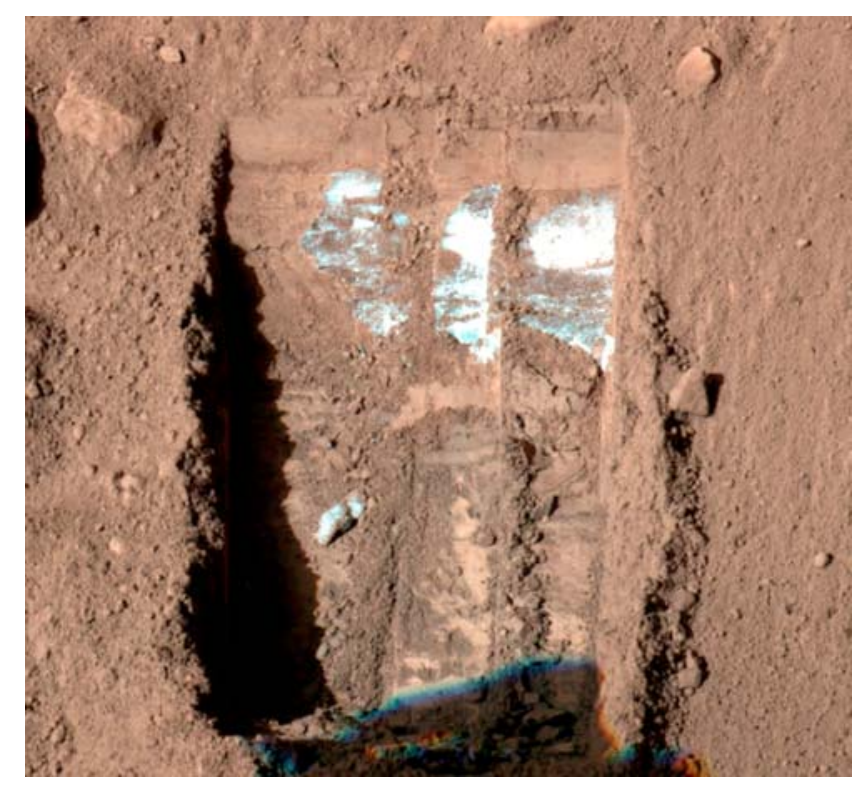

Figure 6. Sol 19 Surface Stereo Imager (SSI) image of the first trench dug by the Phoenix RA. Ice was exposed and removed with little effort, suggesting that it was either saline ice or layered (segregated) ice formed in the presence of brines (more brittle or softer than freshwater ice). The RA scoop broke the chunk of ice seen on the trench into small pieces that sublimated after a few sols because the trench is directly exposed to solar radiation. However, the segregated ice on the trench sublimed extremely slowly (months), suggesting that it might have been salty. Ice exposed on a second trench was extremely hard and could be removed only with great effort and the use of a special drill, suggesting that it was not brine, soft, or brittle ice. 


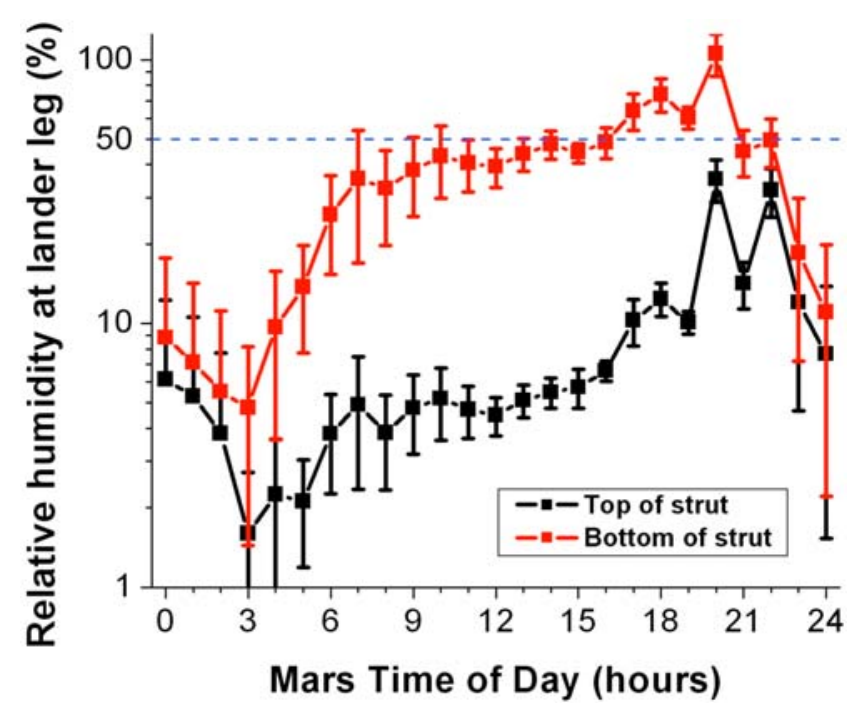

Figure 7. Diurnal variation of $R H$ at top of the strut (where particles do not grow), and near the middle of the strut (where spheroids grow). The $R H$ is based on humidity measurements by the TECP during the first 100 sols of the Phoenix mission and our estimation of the strut temperature. The temperature at the top of the strut was assumed to be equal to that of an engineering sensor at the bottom of the instrument deck, close to it. The temperature at the middle of the strut was calculated by linearly interpolating the temperature at the top with that of the leg as indicated in Figure 8 . The horizontal blue line is the approximate deliquescence relative humidity $R H_{D}$ for magnesium perchlorate.

Edwards et al., 1975, 1978; Xu and Goswami, 1999] would force them to evaporate quickly, leaving only trace amounts in the soil. Indeed, since any temperature the fugacity of ammonia is much larger than that of water, ammonia in concentrated aqueous solutions would therefore evaporate quickly into the ammonia-free Martian atmosphere and hence inhibit deliquescence. This idea is supported by the fact that the Phoenix's WCL and Thermal Evolved Gas Analyzer (TEGA) did not detect any sign of ammonia or their hydrates in soil altered by the Phoenix landing thrusters [Boynton et al., 2009; Hecht et al., 2009; Smith et al., 2009]. It is possible that unknown chemical reactions between the hot gases of the Phoenix thruster plume and the subsurface ice or soil could produce deliquescent materials as discussed in section 3. However, it is unlikely that this happened because Phoenix did not detect any material that might have been formed by these processes in samples of soil disturbed by its thruster plumes. In addition, as mentioned in section 3 the total amount of ammonia ejected during Phoenix's terminal descent (Mehta et al., submitted manuscript, 2009) correspond to a mass fraction of the disturbed soil smaller than that of the perchlorate salts detected by Phoenix.

\section{Broader Implications and Speculations}

[27] Figure 6 shows an image of the ice exposed on the first trench excavated by the Phoenix's RA. The ice in this trench was either softer or more brittle than that of other trenches (such as the trench shown in Figure 9) that were so hard that material from them could be removed only with a special drill (a rasping tool). One interpretation is that this ice was softer or more brittle because it was made of salty water. This could occur because brine pockets makes salty ice to be more brittle than freshwater ice [Wankat, 1973], or because eutectic mixtures freeze into thin layers $(\sim \mu \mathrm{m}$ thick) of the solid phases that the melt separates into that are softer than freshwater ice [Adkins, 1983]. Another interpretation is that it is pure segregated ice formed in the presence of brines because the landing site is too cold for pure water to flow, whereas brines can cycle between freeze and thaw. If any of these interpretations are correct, they would indicate that liquid saline have been present in the undisturbed subsurface of Mars' polar region. However, other explanations for the softness or brittleness of this ice that do not involve brines, such as larger porosity, are also possible.

[28] Neutron flux measurements by Odyssey's Neutron Spectrometer indicate that the Martian soil has large amounts of hydrogen [Boynton et al., 2002]. It has been argued that this implies that the soil of the polar region of Mars contains about $30-50 \%$ of ice by mass in the topmost meter [Feldman et al., 2004]. The presence of large amounts of highly hydrated salts is consistent with the amounts of water calculated from Odyssey's measurements. Indeed, this is also in accordance with the discovery of a 3$18 \mathrm{~cm}$ deep layer of soil on top of subsurface ice at the Phoenix landing site. Therefore, eutectic solutions of ex-

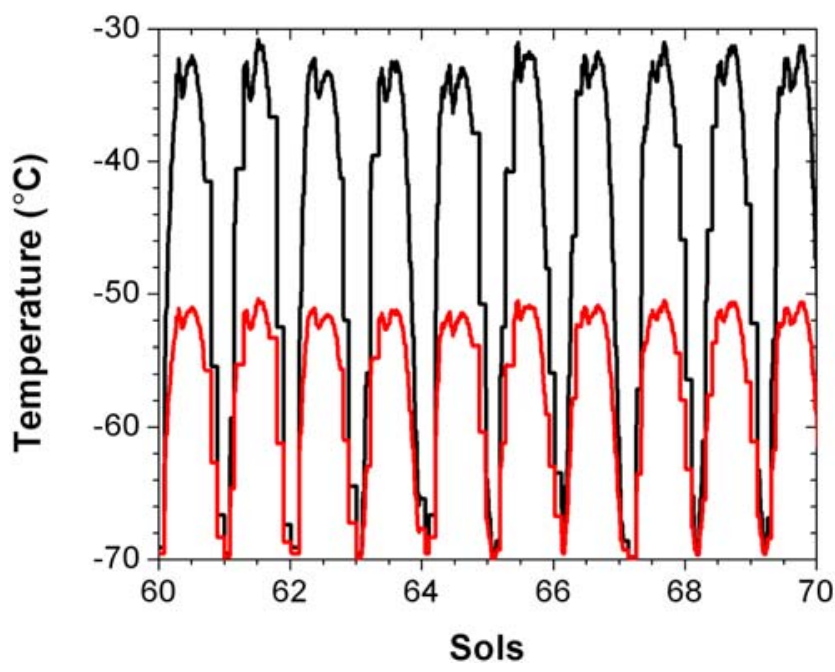

Figure 8. Diurnal variation of temperature at top of the strut (black), where spheroids do not appear to grow, and near the middle of the strut (red), where spheroids grow. The temperature at the top of the strut was assumed to be equal to that of a nearby engineering sensor at the bottom of the instrument deck. The temperature at the middle of the strut was calculated by linearly interpolating the temperature at its top with that of the leg. The leg temperature was assumed to be $-70^{\circ} \mathrm{C}$ because it is sitting on a $\sim 5 \mathrm{~cm}$ thick layer of soil on top of ground ice. The peak temperature at the middle of the strut could be up to $\sim 5^{\circ} \mathrm{C}$ lower if heat transfer by radiation is more important than by conduction. 


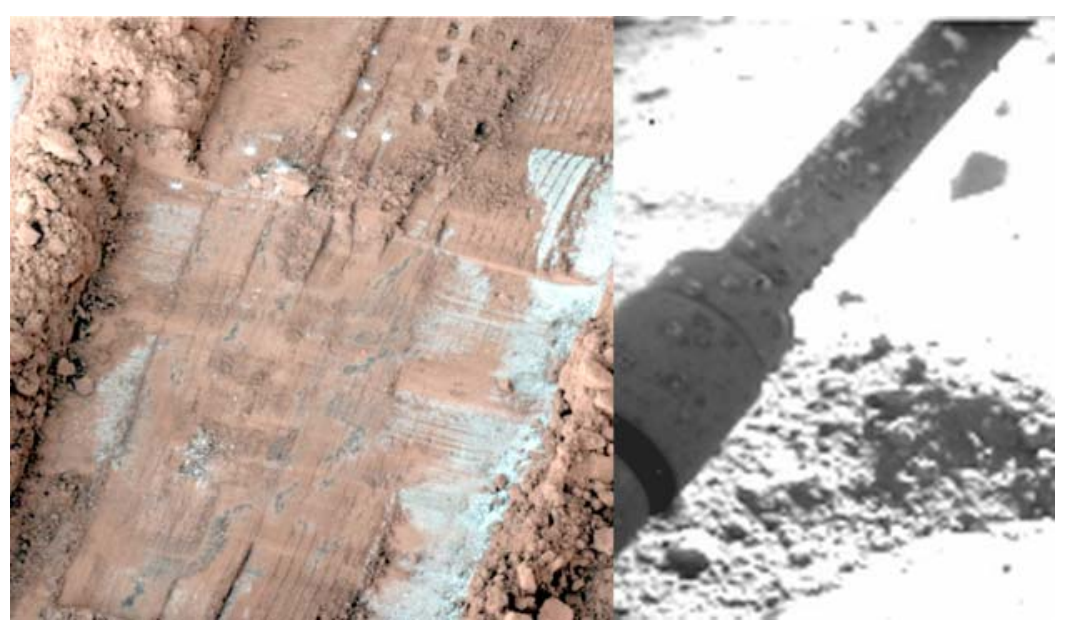

Figure 9. (left) SSI image of frost on Sol 143 and (right) RAC image of spheroids on Sol 142. Note that some of the spheroids present very dark features (they are not missing pixels). This is what would be expected if ice precipitated from the solution as the temperature decreased, leaving pockets of highly saline liquid solutions behind.

tremely deliquescent salts with freezing temperatures lower than $200 \mathrm{~K}$ might be more common on Mars than hitherto believed.

\section{Appendix A: Stability of Liquid Spheroids on Mars}

[29] The calculations presented below show that spheroids of saline aqueous solutions with diameters of up to about $35 \mathrm{~mm}$ are gravitationally stable on horizontal surfaces at the environmental conditions of the Phoenix landing site. Moreover, it shows that spheroids with diameters of up to about $10 \mathrm{~mm}$ are stable on vertical surfaces.

[30] The maximum thickness or height of liquid spheroids on a horizontal surface can be calculated from the data presented in Figure 1 of the article by Padday and Pitt [1974]. The spheroid thickness is

$$
h_{\text {Max }}: \sqrt{\frac{4 \gamma}{\rho_{\text {liq }} g}},
$$

where $\gamma$ is the surface tension of liquid water and $g$ the planet's gravitational acceleration. Padday and Pitt [1974] show that the diameter of these spheroids is approximately $d_{\text {Max }} \sim 3 h_{\text {Max }}$. Taking typical values for pure water under Earth conditions, $\gamma=7.5 \times 10^{-2} \mathrm{~N} \mathrm{~m}^{-1}, \rho_{\text {liq }}=10^{3} \mathrm{~kg} \mathrm{~m}^{-3}$, and $g=9.8 \mathrm{~m} \mathrm{~s}^{-2}$, we find $h_{\text {Max }} \sim 5.6 \mathrm{~mm}$ and $d_{\text {Max }} \sim$ $16.8 \mathrm{~mm}$. Under similar conditions, spheroids would be much larger on Mars because $\mathrm{g}=3.7 \mathrm{~m} \mathrm{~s}^{-2}$. In this case, we find $h_{\mathrm{Max}} \sim 9 \mathrm{~mm}$ and $d_{\mathrm{Max}} \sim 27 \mathrm{~mm}$. Thus, just because of the smaller gravitational acceleration, Martian spheroids can be almost twice as large on horizontal surfaces as terrestrial spheroids.

[31] Because surface tension increases with the salt concentration of aqueous solutions, and decreases with temperature, colder saline spheroids can be larger. Data available in the literature [Washburn, 2003] suggest that the surface tension increases at a rate of $\sim 1.5 \times 10^{-4} \mathrm{~N} \mathrm{~m}^{-1} \mathrm{~K}^{-1}$. Thus, at $\sim 200 \mathrm{~K}$ the surface tension of pure liquid water is $\gamma \sim 8.510^{-2} \mathrm{~N} \mathrm{~m}^{-1}$. Since to the best of our knowledge surface tension data for concentrated solutions of magnesium perchlorate is not available in the literature we use data for $\mathrm{MgCl}_{2}$, a salt with similar ions and charges, in our calculation. This data suggests that at $20^{\circ} \mathrm{C}$ the surface tension of a eutectic solution of $\mathrm{MgCl}_{2}$ is $1.3 \times 10^{-2} \mathrm{~N} \mathrm{~m}^{-1}$ larger than that of pure water [Washburn, 2003]. Combining these two effects, we find that the surface tension on saline spheroids observed on the Phoenix strut is $\gamma \sim 9.5 \times$ $10^{-2} \mathrm{~N} \mathrm{~m}^{-1}$. This increases the surface tension on the spheroids by almost $30 \%$ of the value for pure water at $20^{\circ} \mathrm{C}$. It follows from these calculations that spheroids of $h_{\text {Max }} \sim 10 \mathrm{~mm}$ and $d_{\text {Max }} \sim 35 \mathrm{~mm}$ are stable on the flat portions of the strut.

[32] A few of the spheroids observed on the strut are attached to surfaces that are almost vertical. Next we calculate the maximum size of gravitationally stable spheroids on sloping surfaces to verify if all spheroids observed on the strut are stable when liquid. ElSherbini and Jacobi [2006] show that the maximum nondimensional volume or volume Bond number of a spheroid on a vertical surface is $B \sim 0.9$, which occurs for an advancing contact angle of $\sim 80^{\circ}$. Moreover, they show that the maximum volume of gravitationally stable spheroids is

$$
V_{\operatorname{Max}}:\left(\frac{\gamma B}{\rho g \sin \alpha}\right)
$$

where $\alpha$ is the surface angle with respect to the horizontal. Goodwin et al. [1988] show that these spheroids are larger along the axis parallel to the gravity acceleration vector by about $50 \%$ with respect to the axis perpendicular to it. It follows, from equation (A2) that for a vertical surface on the strut $V_{\text {Max }} \sim 100 \mathrm{~mm}^{3}$. Thus, spheroids of up to about $9 \mathrm{~mm}$ in diameter are gravitationally stable on the vertical portions of the strut. The largest spheroid observed on the vertical portions of the strut is the one labeled 7 in Figure 2. This spheroid has $d_{\text {Max }} \sim 10 \mathrm{~mm}$, on Sol 44. Since the error in our calculation is of the order of $10 \%$ and the slope of the 
cylindrical surface where spheroid 7 is located is less than $90^{\circ}$, our analysis suggests that a liquid spheroid of this size is stable.

[33] The calculations presented in the main text show that even the largest spheroids observed in the strut should be gravitationally stable if not perturbed. Moreover, they suggest that these spheroids have diameter to thickness aspect ratio of about $3: 1$. Thus, the increases in diameters by factors ranging from 1.5 to 2.0 , observed between sols 8 and 44, increases the spheroids' volume by factors ranging from $\sim 3$ to 8 . Independent thermodynamic calculations presented below support the idea that the spheroids' growth is caused by deliquescence.

[34] Acknowledgments. We thank NASA for funding the Phoenix mission, including this study, and for funding M. Mehta though a Graduate Research Fellowship. Graduate student J. Kok was funded by NSF award ATM 0622539. We thank Robb Gillespie and Steven Rogacki for their assistance with the laboratory experiments on the Phoenix landing thruster. We thank Lucas Renno for help with the interpretation of the images of the spheroids. Finally, we thank John Barker and three anonymous reviewers for constructive criticisms and suggestions that improved the manuscript substantially.

\section{References}

Adkins, C. J. (1983), Equilibrium Thermodynamics, 3rd ed., 285 pp., Cambridge Univ. Press, Cambridge, U. K.

Besley, L. M., and G. A. Bottomley (1969), The water vapour equilibria over magnesium perchlorate hydrates, J. Chem. Thermodyn., 1, 13-19, doi:10.1016/0021-9614(69)90032-9.

Boynton, W. V., et al. (2002), Distribution of hydrogen in the near surface of Mars: Evidence for subsurface ice deposits, Science, 297, 81-85, doi:10.1126/science.1073722.

Boynton, W. V., et al. (2009), Evidence for calcium carbonate at the Phoenix landing site, Science, 325, 61-64, doi:10.1126/science.1172768.

Braban, C. F., J. P. D. Abbatt, and D. J. Cziczo (2001), Deliquescence of ammonium sulfate particles at subeutectic temperatures, J. Geophys. Res., $28,3879-3882$.

Brass, G. W. (1980), Stability of brines on Mars, Icarus, 42, 20-28, doi:10.1016/0019-1035(80)90237-7.

Bryson, K. L., V. Chevrier, D. W. G. Sears, and R. Ulrich (2008), Stability of ice on Mars and the water vapor diurnal cycle: Experimental study of the sublimation of ice through a fine-grained basaltic regolith, Icarus, 196, 446-458, doi:10.1016/j.icarus.2008.02.011.

Bushuyev, A. V., N. A. Volkov, and V. S. Loshchilov (1974), Atlas of Sea Ice Formation, Gidrometeoizdat, Saint Petersburg, Russia.

Chevrier, V. F., and T. S. Altheide (2008), Low temperature aqueous ferric sulfate solutions on the surface of Mars, Geophys. Res. Lett., 35, L22101, doi:10.1029/2008GL035489.

Clark, B. C. (1978), Implications of abundant hygroscopic minerals in the Martian regolith, Icarus, 34, 645-665, doi:10.1016/0019-1035(78) 90052-0.

Clark, B. C., and D. C. Van Hart (1981), The salts of Mars, Icarus, 45, 370-378, doi:10.1016/0019-1035(81)90041-5.

Clausse, D., I. Sifrini, and J. P. Dumas (1987), On the study by DSC of the unexpected ice melting at $0^{\circ} \mathrm{C}$ of emulsified aqueous saline solutions, Thermochim. Acta, 122, 123-133, doi:10.1016/0040-6031(87)80112-0.

Cohen, M. D., R. C. Flagan, and J. H. Seinfeld (1987), Studies of concentrated electrolyte solutions using the electrodynamic balance: 2 . Water activities for mixed-electrolyte solutions, J. Phys. Chem., 91, 45754582, doi:10.1021/j100301a030.

Cziczo, D. J., J. B. Nowak, J. H. Hu, and J. P. D. Abbatt (1997), Infrared spectroscopy of model tropospheric aerosols as a function of relative humidity: Observation of deliquescence and crystallization, J. Geophys. Res., 102, 18,843-18,850, doi:10.1029/97JD01361.

Dickinson, W. W., and M. R. Rosen (2003), Antarctic permafrost: An analogue for water and diagenetic minerals on Mars, Geology, 31, 199-202, doi:10.1130/0091-7613(2003)031<0199:APAAFW >2.0.CO;2.

Edwards, J., J. Newman, and J. M. Prausnitz (1975), Thermodynamics of aqueous solutions containing volatile weak electrolytes, AIChE J., 21, $248-259$.

Edwards, J., G. Maurer, J. Newman, and J. M. Prausnitz (1978), Vaporliquid equilibria in multicomponent aqueous solutions of volatile weak electrolytes, AIChE J., 24, 966-976.
ElSherbini, A. I., and A. M. Jacobi (2006), Retention forces and contact angles for critical liquid drops on non-horizontal surfaces, J. Colloid Interface Sci., 299, 841-849, doi:10.1016/j.jcis.2006.02.018.

Farmer, C. B. (1976), Liquid water on Mars, Icarus, 28, 279-289, doi:10.1016/0019-1035(76)90038-5.

Feldman, W. C., et al. (2004), Global distribution of near-surface hydrogen on Mars, J. Geophys. Res., 109, E09006, doi:10.1029/2003JE002160.

Gooding, J. L., S. J. Wentworth, and M. E. Zolensky (1991), Aqueous alteration of the Nakhla meteorite, Meteoritics, 26, 135-143.

Goodwin, R., D. Rice, and S. Middleman (1988), A model for the onset of motion of a sessile liquid drop on a rotating disk, J. Colloid Interface Sci., 125, 162-169, doi:10.1016/0021-9797(88)90065-3.

Goudie, A. S. (1986), Laboratory simulation of 'the wick effect' in salt weathering of rock, Earth Surf. Processes Landforms, 11, 275-285, doi:10.1002/esp.3290110305.

Grimm, R. E., and D. E. Stillman (2008), On the origin of widespread subsurface radar attenuation at Mars, Lunar Planet. Sci., XXXIX, Abstract 2251 .

Haberle, R. M., C. P. McKay, J. Schaeffer, N. A. Cabrol, E. A. Grin, and A. P. Zent (2001), On the possibility of liquid water on present-day Mars, J. Geophys. Res., 106, 23,317-23,326, doi:10.1029/2000JE001360.

Hecht, M. H., S. P. Kounaves, R. C. Quinn, S. J. West, S. M. M. Young, D. W. Ming, D. C. Catling, B. C. Clark, and P. H. Smith (2009), Detection of perchlorate and the soluble chemistry of Martian soil: Findings from the Phoenix Mars Lander, Science, 325, 64, doi:10.1126/science. 1172466 .

Husted, R. R., and P. V. Fennessey (1977), Site aleration effects from rocket exhaust impingement during a simulated Viking Mars landing: Part II. Chemical and biological site alteration, NASA CR-2814, $48 \mathrm{pp}$.

Jezek, K. C., and G. Koh (1987), Effects of water and ice layers on the scattering properties of diffuse reflectors, Appl. Opt., 26, 5143-5147, doi:10.1364/AO.26.005143.

Keller, H. U., et al. (2009), Physical properties of the icy soil at the Phoenix landing site, Lunar Planet. Sci., 40th, Abstract 1671.

Koop, T., A. Kapilashrami, L. T. Molina, and M. J. Molina (2000), Phase transitions of sea-salt/water mixtures at low temperatures: Implications for ozone chemistry in the polar marine boundary layer, J. Geophys. Res., $105,26,393-26,402$, doi:10.1029/2000JD900413.

Lide, D. R. (2008a), Thermal conductivity of gases, in CRC Handbook of Chemistry and Physics, 88th ed., pp. 6.184-6.185, Taylor and Francis, Boca Raton, Fla.

Lide, D. R. (2008b), Diffusion in gases, in CRC Handbook of Chemistry and Physics, 88th ed., 6.191-6.192, Taylor and Francis, Boca Raton, Fla Markiewicz, W. J., et al. (2009), Sublimation of exposed snow queen surface water ice as observed by the Phoenix Mars Lander, Lunar Planet. Sci., 40th, Abstract 1667.

Marrero, T. R., and E. A. Mason (1972), Gaseous diffusion coefficients, J. Phys. Chem. Ref. Data, 1, 3-118.

Mellon, M. T., W. C. Feldman, and T. H. Prettyman (2004), The presence and stability of ground ice in the southern hemisphere of Mars, Icarus, 169, 324-340, doi:10.1016/j.icarus.2003.10.022.

Moore, J. M., and M. A. Bullock (1999), Experimental studies of Marsanalog brines, J. Geophys. Res., 104, 21,925-21,934, doi:10.1029/ 1999JE001040.

Padday, J. F., and A. Pitt (1974), Sessile drop profiles: A comparison with Searle's equation for drop height, J. Colloid Interface Sci., 48, 170-171, doi:10.1016/0021-9797(74)90340-3.

Perovich, D. K., T. C. Grenfell, B. Light, and P. V. Hobbs (2002), Seasonal evolution of the albedo of multiyear Arctic sea ice, J. Geophys. Res., 107(C10), 8044, doi:10.1029/2000JC000438.

Pestova, O. N., L. A. Myund, M. K. Khripun, and A. V. Prigaro (2005), Polythermal study of the systems $\mathrm{M}\left(\mathrm{ClO}_{4}\right)_{2}-\mathrm{H}_{2} \mathrm{O}\left(\mathrm{M}^{2+}=\mathrm{Mg}^{2+}, \mathrm{Ca}^{2+}\right.$, $\left.\mathrm{Sr}^{2+}, \mathrm{Ba}^{2+}\right)$, Russ. J. Appl. Chem., Engl. Transl., 78, 409-413.

Plemmons, D. H., M. Mehta, B. C. Clark, S. P. Kounaves, L. L. Peach Jr., N. O. Renno, L. K. Tamppari, and S. M. M. Young (2008), Effects of the Phoenix Lander descent thruster plume on the Martian surface, J. Geophys. Res., 113, E00A11, doi:10.1029/2007JE003059.

Rao, M. N., S. R. Sutton, D. S. McKay, and G. Dreibus (2005), Clues to Martian brines based on halogens in salts from nakhlites and MER samples, J. Geophys. Res., 110, E12S06, doi:10.1029/2005JE002470.

Renno, N. O., et al. (2009), Physical and thermodynamical evidence for liquid water on Mars, Lunar Planet. Sci., 40th, Abstract 1440.

Rogers, R. R. (1979), A Short Course in Cloud Physics, 2nd ed., 235 pp., Pergamon, New York.

Romine, G. L., and J. Gliozzi (1973), Site aleration effects from rocket exhaust impingement during a simulated Viking Mars landing: Part I. Nozzle development and physical site alteration, NASA CR-2252.

Seinfeld, J. H., and S. N. Pandis (2006), Atmospheric Chemistry and Physics: From Air Pollution to Climate Change, 2nd ed., 1203 pp. Wiley, New York. 
Smith, P. H., et al. (2009), $\mathrm{H}^{2} \mathrm{O}$ at the Phoenix landing site, Science, 325, 58-61, doi:10.1126/science.1172339.

Tang, I. N., A. C. Tridico, and K. H. Fung (1997), Thermodynamic and optical properties of sea-salt aerosols, J. Geophys. Res., 102, 23,26923,275, doi:10.1029/97JD01806.

Wankat, P. C. (1973), Desalination by natural freezing, Desalination, 13, 147-157, doi:10.1016/S0011-9164(00)82041-X.

Washburn, E. W. (2003), International Critical Tables of Numerical Data, Phsyics, Chemistry and Technology, Knovel, New York.

Wentworth, S. J., E. K. Gibson, M. A. Velbel, and D. S. McKay (2005), Antarctic dry valleys and indigenous weathering in Mars meteorites: Implications for water and life on Mars, Icarus, 174, 383-395, doi:10.1016/j.icarus.2004.08.026.

Whiteway, J., et al. (2009), Mars water ice clouds and precipitation, Science, 325, 68-70, doi:10.1126/science.1172344.

$\mathrm{Xu}, \mathrm{F}$., and D. Y. Goswami (1999), Thermodynamic properties of ammoniawater mixtures for power-cycle applications, Energy, 24, 525-536, doi:10.1016/S0360-5442(99)00007-9.

B. J. Bos, NASA Goddard Space Flight Center, Greenbelt, MD 20771 , USA.

D. Catling, Department of Earth and Space Sciences, University of Washington, Seattle, WA 98195, USA.

B. C. Clark, Space Science Institute, 4750 Walnut Street, Boulder, CO 80301, USA.
L. Drube, S. F. Hviid, K. Leer, and M. B. Madsen, Niels Bohr Institute, University of Copenhagen, Copenhagen DK-302100, Denmark.

D. Fisher, Geological Survey of Canada, University of Ottawa, Ottawa K1A 0Y3, Canada.

W. Goetz, H. U. Keller, and W. J. Markiewicz, Max Planck Institute for Solar System Research, Max-Planck-Strasse 2, Katlenburg-Lindau D-37191, Germany.

J. F. Kok, M. Mehta, and N. O. Rennó, Department of Atmospheric, Oceanic, and Space Sciences, University of Michigan, Ann Arbor, MI 48103, USA. (renno@alum.mit.edu)

S. P. Kounaves, Department of Chemistry, Tufts University, Medford, MA 02155, USA.

M. Lemmon, Department of Atmospheric Sciences, Texas A\&M University, College Station, TX 77843, USA

J. Marshall, Carl Sagan Center, SETI Institute, 515 North Whisman Road, Mountain View, CA 94043, USA.

C. McKay and C. Stoker, NASA Ames Research Center, Mountain View, CA 94035, USA.

M. Smith, Jet Propulsion Laboratory, California Institute of Technology, Pasadena, CA 91109, USA.

P. H. Smith, Department of Planetary Sciences, University of Arizona, Tucson, AZ 85721, USA.

S. M. M. Young, Department of Chemistry, University of New Hampshire, Durham, NH 03824, USA

M. P. Zorzano, Centro de Astrobiología, CSIC, INTA, Carretera de Torrejón a Ajalvir, km 4, E-28850 Madrid, Spain. 